Article

\title{
Analysis of Precipitation Extremes in the Qinghai-Tibetan Plateau, China: Spatio-Temporal Characteristics and Topography Effects
}

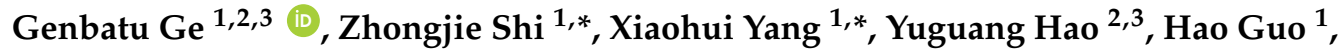 \\ Fandjinou Kossi ${ }^{4,5}$, Zhiming Xin ${ }^{2,3}$, Wei Wei ${ }^{4}$, Zhiyong Zhang ${ }^{1}$, Xiao Zhang ${ }^{1}$, Yanshu Liu ${ }^{1}$ and \\ Junhui Liu 6 \\ 1 Institute of Desertification Studies, Chinese Academy of Forestry, Beijing 100091, China; \\ gegbt@hotmail.com (G.G.); guohaomail@163.com (H.G.); zzy100083@163.com (Z.Z.); \\ zhangxiao978@caf.ac.cn (X.Z.); liuyanshu@caf.ac.cn (Y.L.) \\ 2 Experimental Center for Desert Forestry, Chinese Academy of Forestry, Dengkou 015200, China; \\ hyuguang@163.com (Y.H.); xzmlkn@163.com (Z.X.) \\ 3 Desert Ecosystem Research Station, Inner Mongolia State Forestry Administration, Dengkou 015200, China \\ 4 College of Water and Soil Conservation, Beijing Forestry University, Beijing 100083, China; \\ fandnew@yahoo.fr (F.K.); weiwei@bjfu.edu.cn (W.W.) \\ 5 Laboratoire de Biologie Végétale, Université de Lomé, Lome BP1515, Togo \\ 6 Chinese Research Academy of Environmental Sciences, Beijing 100012, China; liujh@craes.org.cn \\ * Correspondence: shizj@caf.ac.cn (Z.S.); Yangxh@caf.ac.cn (X.Y.); Tel.: +86-10-6282-4106 (Z.S.); \\ +86-10-6282-4059 (X.Y.); Fax: +86-10-6282-4016 (Z.S.); +86-10-6282-4059 (X.Y.)
}

Received: 27 May 2017; Accepted: 15 July 2017; Published: 19 July 2017

\begin{abstract}
Although precipitation extremes exert a major influence on populations and the environment, trend analysis for the entire Qinghai-Tibetan plateau (QTP) has not previously been undertaken. In this study, meteorological data from 83 weather stations was used to analyze the temporal trends and spatial distribution of 10 extreme precipitation indices over the QTP during 1975-2014. The Mann Kendall test and Sen's slope estimator were used to determine significances and magnitudes of station trends. Spatially, stations recording increasing trends were mainly distributed in the southwestern, central and northern regions. Stations with decreasing trends were centered on the eastern and southeastern areas. Temporally, all indices had an increasing trend except for consecutive dry days (CDD) and consecutive wet days (CWD) during the study period. The contribution of extreme precipitation to total precipitation showed a significant increasing trend. These findings may be due to the complex interaction between the large-scale circulation and topography. In general, the changes of extreme precipitation indicated an enhanced tendency, with the frequency, intensity and amount of heavy precipitation increasing over time. Furthermore, altitude dependency of extreme precipitation does not exist in QTP, with topography effects on changes in precipitation extremes being more obvious in the higher elevation, flat, and hill stations.
\end{abstract}

Keywords: extreme precipitation; spatiotemporal trend; Qinghai-Tibetan plateau; Mann-Kendall test; Sen's slope estimator; topography

\section{Introduction}

Variability and trends in extreme climatic events, being more sensitive to climate change than those of mean values, have gained more attention in recent years [1]. This focus is important as extreme climatic events pose numerous hazards for human populations and natural ecosystems [2]. Precipitation extremes are especially important because of their natural hazard-related impacts, such as droughts, floods, severe erosion, and economic-related impacts such as agriculture and 
water resources [3-6]. Generally, trends of precipitation extremes are more difficult to detect than that of temperature extremes, because changes in precipitation exhibit much less spatial coherence [7]. Consequently, current research on climate has focused on assessing the changes in extreme precipitation with the aim to understanding their mechanisms in order to minimize environmental problems and other issues, and to provide more information for adaptive measures.

Global scale extreme precipitation variability and trends have shown a widespread and significant increase; the frequency of heavy precipitation events in many areas, particularly in mid-latitude regions, have increased [8,9]. Country-wide results from North America [10] and China [11] reflect these global observations; $\mathrm{Li}$ et al. [12] however recorded decreasing annual precipitation and the frequency of heavy precipitation days in Yunnan, China. Results from the Asia-Pacific Network region [13] and across Europe [14] also did not detect any systematic trends for total precipitation, frequency, and duration of extreme precipitation events. Variations in results from these investigations show that differences of study area in precipitation extremes can be great, and that changes in particular regions are not consistent. Understanding the changes in extreme climate events at a particular region is important to establish countermeasures to adapt to the impacts of climate change.

The Qinghai-Tibetan plateau (QTP), containing a unique topography at a high altitude, plays an important role in the regional climate of East and South Asia, as well as on the atmospheric circulation of the Northern Hemisphere $[15,16]$. The QTP is considered a sensitive region to global change, characterized as the driving force or amplifier for global change [17]. The QTP also exerts a major influence on moisture transport from the Indian Ocean to East Asia [18]; the upper atmospheric moisture transport affects the global environment [19]. Rivers originating from the QTP are important water sources for nearly $40 \%$ of the global population; precipitation, especially extreme precipitation-related river discharges [19], vegetation phenology [20], and natural hazards [21] have an important effect on local populations. Due to the importance of this area, and its effect upon populations, more focus has been paid to climate change of the QTP. Previous investigations showed a statistically significant warming trend $\left(0.36^{\circ} \mathrm{C} /\right.$ decade $)$ over the QTP from 1960-2007 [22]. This warming trend exceeded global warming trends $\left(0.13^{\circ} \mathrm{C} /\right.$ decade; [23] $)$ and the warming trend recorded across China $\left(0.26^{\circ} \mathrm{C} /\right.$ decade; [24]). Precipitation trends over the QTP recorded large regional differences from 1961-2001; increased trends were observed for most regions, especially in eastern and central areas, while the western areas exhibited a decreased trend [25]. However, some investigations on extreme precipitation only involved partial areas of the QTP [26-29], and precipitation extremes for the entire QTP separated from China have not been previously investigated in detail. Moreover, many studies have confirmed the impact of complex topography over the QTP on spatiotemporal variations of precipitation [30-32]; nevertheless, whether and what kind of topographical influence exists in relation to changes of extreme precipitation still needs further study. Zhang et al. reported there was a negative correlation between precipitation extremes and elevation in the Hengduan Mountains region [29]. Li et al. showed that extreme precipitation events mainly increased at lower altitude, and obvious changes existed at summit, flat and valley stations in southwestern China [33]. Hence, similar altitude dependency and topography effects were expected to be true in the QTP. In order to fully understand the spatial and temporal trends of extreme precipitation and their correlates to topography in the QTP, more in-depth investigations are required.

The objectives of this investigation were to (1) analyze the spatial and temporal variations in the changing characteristics of precipitation extremes in the QTP; (2) examine the relationship between topography and trends in indices of precipitation extremes in the QTP. The study will increase our understanding on the changes of precipitation extremes under the impact of climate change. 


\section{Experiments}

\subsection{Study Area}

The Qinghai-Tibetan Plateau (QTP) (26 02" $\left.-39^{\circ} 46^{\prime \prime} \mathrm{N}, 73^{\circ} 18^{\prime \prime}-104^{\circ} 47^{\prime \prime} \mathrm{E}\right)$, located in southwestern China (Figure 1), has an area approximately $2.4 \times 10^{6} \mathrm{~km}^{2}$ and includes Tibet, Qinghai, and areas of Yunnan, Sichuan, Gansu and Xinjiang. The QTP has an average elevation of over $4000 \mathrm{~m}$ and it has been termed "the Third Pole" or the "Roof of the World" [34,35]. The QTP is surrounded by large mountains, such as the Kunlun Mountains, the Qilian Mountains, the Himalaya Mountains, and the Hengduan Mountains. Many rivers originate from the QTP, such as the Yangze River, the Yellow River, the YaluZangbo River, the Lancang-Mekong River, and the India River. The QTP is also referred to as the largest high-altitude inland lake area in the word, having more than 1000 lakes greater than $1 \mathrm{~km}^{2}$ in area [36]. More than $13 \times 10^{4} \mathrm{~km}^{2}$ of wetland area is distributed across the plateau, also making this area one of the most important wetland ecosystem areas in China [37].

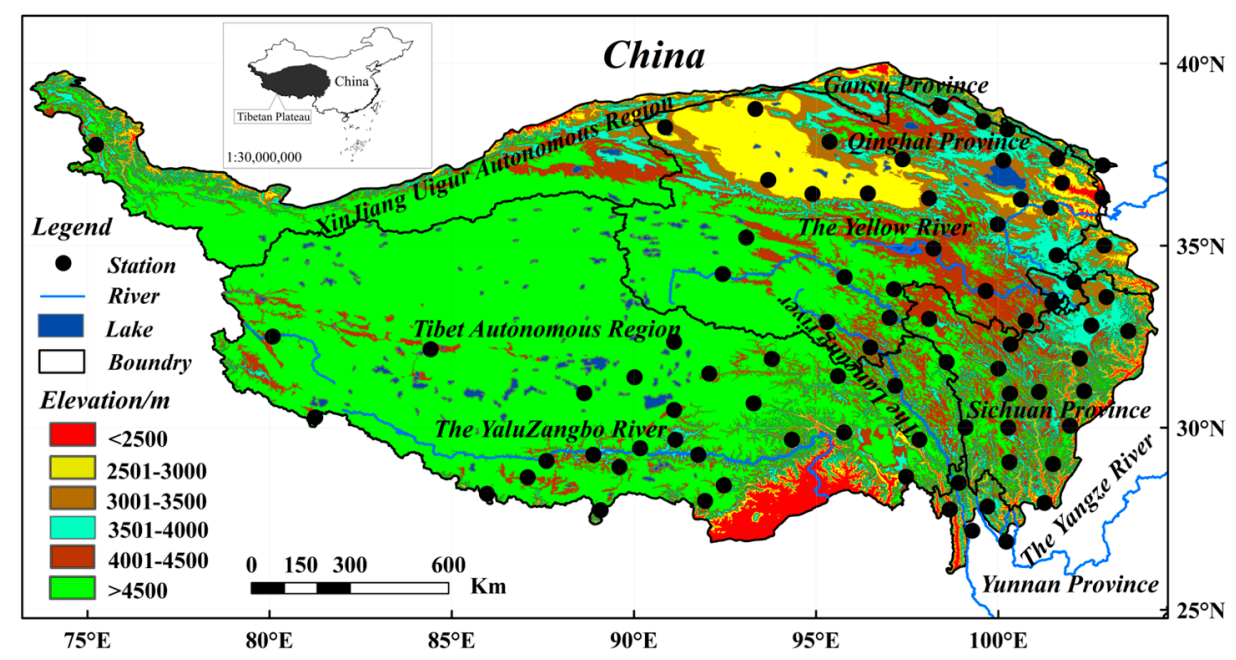

Figure 1. Location of study area and stations.

The QTP has a typical alpine climate, being characterized by warm, rainy summers and cold, dry winters [25]. The southeastern area of the plateau is characterized by humid conditions with arid and semi-arid conditions dominating the northwestern areas. Annual average temperatures increase from the northwest to the southeast and annual average precipitation decreases from over $4000 \mathrm{~mm}$ in the southeast to only $20 \mathrm{~mm}$ in the northwest (Qaidam Basin) [38].

\subsection{Data Source}

Daily precipitation data spanning 1960-2014 from total 135 weather stations were obtained from the National Climate Center of China Meteorological Administration (Available online: http:/ / data.cma.cn/). The World Meteorological Organization defined a normal climate as being the mean of climatological variables over a 30-year-period [39], therefore for our investigation, stations which ceased to operate during the study period, or established after 1990, were not selected. As the majority of weather stations distributed in the Tibet autonomous region were commissioned in the 1970s, to attain an applicable balance between the spatial coverage of stations and length of time series, 83 stations with data spanning 1975-2014 were eventually used. Figure 1 shows the locations of these weather stations. 


\subsection{Data Quality and Homogeneity Test}

To ensure that the best possible data sources were used, quality control was performed using the RClimDex package developed by the CCl/CLIVAR/JCOMM Expert Team (ET) on Climate Change Detection and Indices ETCCDI [40] to identify errors in data processing, such as errors in manual keying [8]. Initially, missing values were checked by a graphical method and replaced with an internal format (currently coded as -99.9 ), and daily precipitation data with negative values were flagged as erroneous. Any obvious outliers which were identified in the daily precipitation data by examination of visual data graphs and histograms were checked manually. On the basis of statistical tests, local knowledge and data from neighboring stations, identified suspicious outliers were corrected and removed.

The aim of the homogeneity test is to eliminate the influence of artificial changes that are related to natural variations in climate. Owing to the various types of inhomogeneities, the homogeneity test is extremely complex and difficult to undertake successfully [41]. Inhomogeneities due to step changes, such as station relocation, observing procedures and instrument changes were tested in this study. RHtestV4 [42], which is based on a two-phase regression model with linear trend, was used to identify step changes in the precipitation time series. According to the results of the penalized maximal F (PMF) test, values of PMFmax for all stations were insignificant at the 0.05 level. Thus, the 83 stations selected for analysis in this study passed this test.

\subsection{Indices of Extreme Precipitation}

Ten indices of extreme precipitation recommended by ETCCDI were selected for this study. These indices were derived from daily precipitation and can be divided into five different categories: (1) threshold indices; (2) absolute indices; (3) duration indices; (4) percentile-based indices; and (5) other indices [8]. Table 1 provided the detailed descriptions of above indices. RClimDex was used to calculate the indices after the data quality control and homogeneity test. Moreover, annual contribution from very wet days (R95pT) and extremely wet days (R99pT) were also used in this study, they are defined as $(\mathrm{R} 95 \mathrm{p} / \mathrm{PRCPTOT})^{*} 100$ and $(\mathrm{R} 99 \mathrm{p} / \mathrm{PRCPTOT})^{*} 100$, respectively.

Table 1. Indices of extreme precipitation used in this study.

\begin{tabular}{|c|c|c|c|}
\hline Type & Name & Definition & Units \\
\hline \multirow[t]{2}{*}{ Threshold } & $\begin{array}{c}\text { Number of heavy } \\
\text { precipitation days (R10) }\end{array}$ & Annual count of days when $R R \geq 10 \mathrm{~mm}$ & days \\
\hline & $\begin{array}{l}\text { Number of very heavy } \\
\text { precipitation days (R20) }\end{array}$ & Annual count of days when $\mathrm{RR} \geq 20 \mathrm{~mm}$ & days \\
\hline \multirow{2}{*}{ Absolute } & $\begin{array}{l}\text { Maximum one-day } \\
\text { precipitation amount }(\mathrm{R} \times 1 \mathrm{~d})\end{array}$ & Monthly maximum one-day precipitation & $\mathrm{mm}$ \\
\hline & $\begin{array}{l}\text { Maximum five-day } \\
\text { precipitation amount }(R \times 5 d)\end{array}$ & Monthly maximum consecutive five-day precipitation & $\mathrm{mm}$ \\
\hline \multirow{2}{*}{ Duration } & Consecutive dry days (CDD) & Maximum number of consecutive days with $\mathrm{RR}<1 \mathrm{~mm}$ & days \\
\hline & Consecutive wet days (CWD) & Maximum number of consecutive days with $R R \geq 1 \mathrm{~mm}$ & days \\
\hline \multirow{2}{*}{ Percentile } & Very wet day precipitation (R95p) & $\begin{array}{l}\text { Annual total precipitation when } \mathrm{RR}>95 \mathrm{th} \\
\text { percentile of } 1975-2014 \text { daily precipitation }\end{array}$ & $\mathrm{mm}$ \\
\hline & $\begin{array}{l}\text { Extremely wet day } \\
\text { precipitation (R99p) }\end{array}$ & $\begin{array}{l}\text { Annual total precipitation when } \mathrm{RR}>99 \text { th } \\
\text { percentile of } 1975-2014 \text { daily precipitation }\end{array}$ & $\mathrm{mm}$ \\
\hline \multirow[t]{2}{*}{ Other } & $\begin{array}{l}\text { Annual total wet-day } \\
\text { precipitation (PRCPTOT) }\end{array}$ & Annual total precipitation from wet days ( $R \mathrm{R} \geq 1 \mathrm{~mm}$ ) & $\mathrm{mm}$ \\
\hline & Simple daily intensity index (SDII) & Average precipitation on wet days & mm day ${ }^{-1}$ \\
\hline
\end{tabular}

Abbreviations are as follows: RR, daily precipitation; A wet day is defined when $R R \geq 1 \mathrm{~mm}$. 


\subsection{Statistic Analysis}

A great many statistical methods have been developed to detect the trend in long-time series of hydro-meteorological variables, including parametric and non-parametric methods [43-45]. The non-parametric Mann-Kendall (MK) test [46,47] is a valid tool for assessing the significance of monotonic trends in hydro-meteorological time series; it is suitable for non-normally distributed data, including missing values, and it is less influenced by the presence of outliers in the data [48]). The magnitudes of identified trends were analyzed using Sen's slope estimator [49]. In our study, these two non-parametric methods were applied to analyze trends in precipitation extremes. Both methods require time series to be serially independent, which can be accomplished by using a pre-whitening technique [50]. This process adopts the same procedure proposed by Yue et al. [51] to eliminate the influence of autocorrelation before applying the MK test and Sen's slope estimator. To analyze percentage changes of extreme precipitation to total precipitation on an inter-annual scale, the regional series of the ratio between the precipitation amount on very (extremely) wet days to the total precipitation (R95pT and R99pT) was calculated, and the significance was tested using the MK test.

The correlation between the trend magnitudes in extreme precipitation indices and elevation was analyzed and tested by a non-parametric Kruskal-Wallis test. To investigate whether topography can influence the changes of extreme indices, the relief amplitude was extracted in QTP. Han et al. [52] reported that $1.17 \mathrm{~km}^{2}$ could be the best window area for extraction of relief amplitude in the QTP. In this study, relief amplitude in QTP was extracted at a grid unit of $36 \times 36$ mesh size $\left(1.17 \mathrm{~km}^{2}\right)$ derived from ASTER GDEMV2 data (Available online: http://www.gscloud.cn/). According to the relief amplitude, the 83 stations were classified into four topographic groups: flat $(<30 \mathrm{~m})$, mesa $(30-70 \mathrm{~m})$, hill $(70-200 \mathrm{~m})$, and low rolling mountain $(200-500 \mathrm{~m})$, and the average trend magnitudes of each index in categorized topographic group were tested using a non-parametric Kruskal-Wallis test.

\section{Results}

\subsection{Spatiotemporal Variability and Trends of Extreme Precipitation}

\subsubsection{Threshold Indices}

Regional annual anomaly series was used to examine the temporal evolution of these indices in detail (Figure 2). Figure 2a,b shows temporal variation in the number of heavy precipitation days (R10) and of very heavy precipitation days (R20); R10 and R20 had increasing fluctuations from 1975 to 2014. The trend magnitudes in R10 and R20 were $0.24 \mathrm{~d} /$ decade and $0.07 \mathrm{~d} /$ decade, respectively; however, neither result was significant (Table 2).

The spatial distribution of R10 showed that more than $50 \%$ of stations recorded an increasing trend, and these stations were located in the southeastern and northeastern parts of the QTP. Stations with no identifiable trends were generally scattered across the plateau. Of the stations recording increasing trends, $10 \%$ had a magnitude ranging from 0.66 to $1.76 \mathrm{~d} /$ decade (Figure 3a, Table 2); these were identified as being significant. For R20, about $65 \%$ of stations, being distributed across most of the plateau, showed increasing trends with a magnitude ranging from 0.01 to $0.75 \mathrm{~d} /$ decade. However, only seven stations were significant at the $95 \%$ confidence level (Figure $3 b$ ). About $28 \%$ of stations had a decreasing trend and these were mainly located in the east and southeastern areas of the plateau. The results from these stations had a magnitude ranging from -0.03 to $-1.21 \mathrm{~d} /$ decade; only one station was recorded as being significant at the 0.05 significance level. 

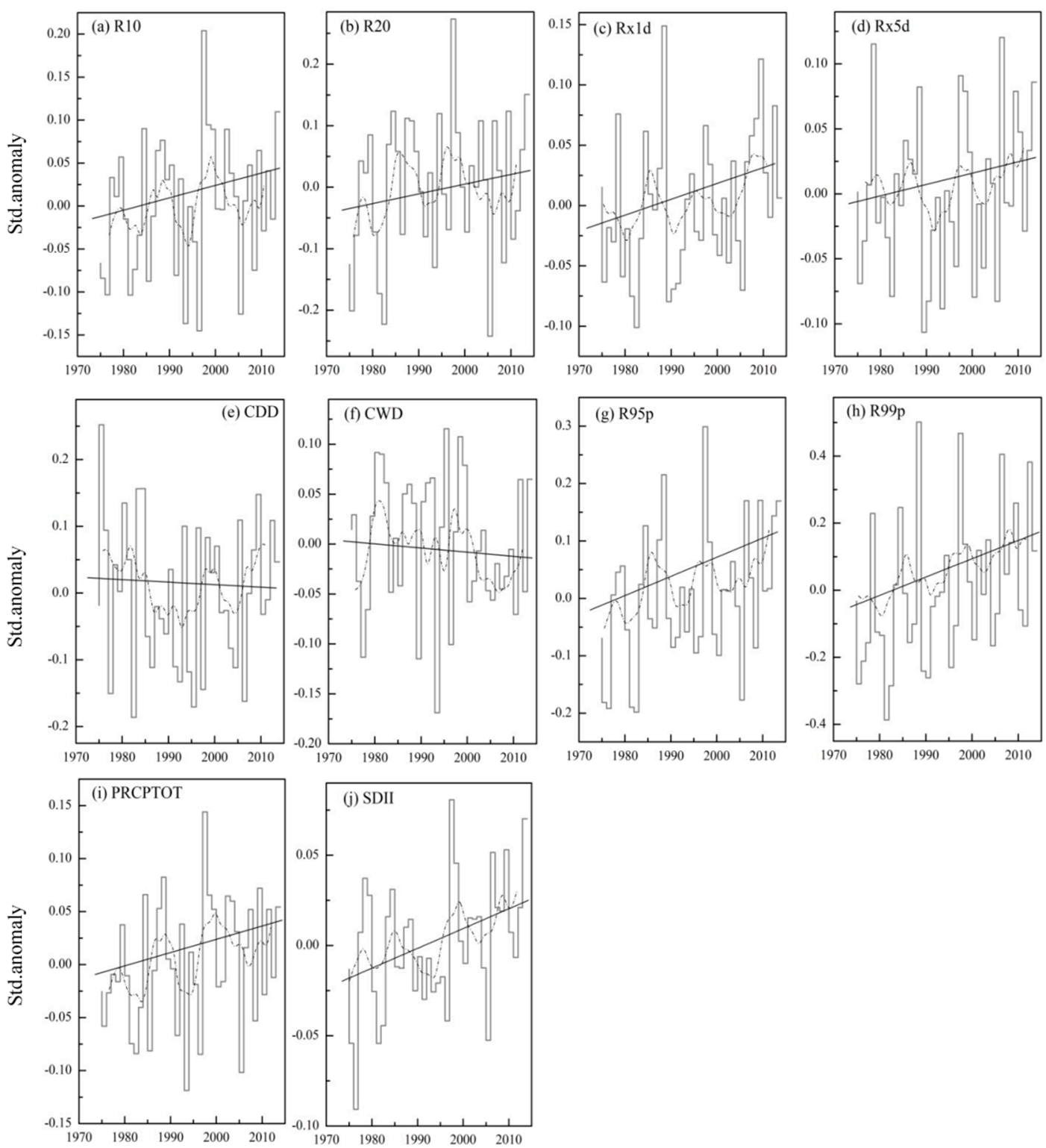

Figure 2. Regionally averaged anomaly series of the 10 indices, 1975-2014. (a) R10; (b) R20; (c) R $\times 1$; (d) R×5d; (e) CDD; (f) CWD; (g) R95p; (h) R99p; (i) PRCPTOT; and (j) SDII. The dotted line is the five-year smoothing average and the black line is the linear trend. 

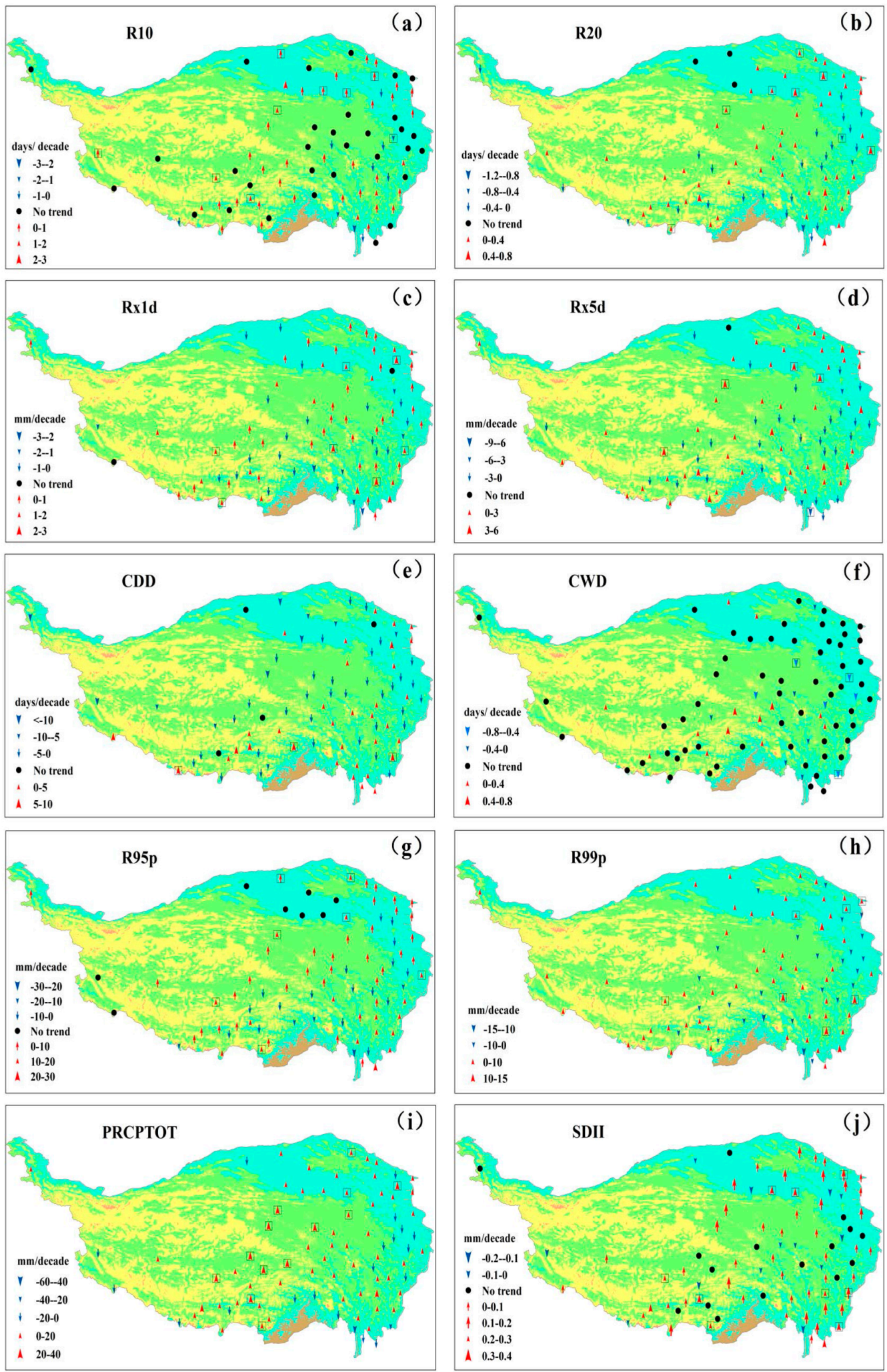

Figure 3. Spatial patterns of magnitude of trend for the indices of extreme precipitation, 1975-2014 for (a) R10; (b) R20; (c) R×1d; (d) R×5d; (e) CDD; (f) CWD; (g) R95p; (h) R99p; (i) PRCPTOT; and (j) SDII. Signs are scaled according to the magnitude of trend. Color coding is as follows: blue corresponds to decreasing trends, red to increasing trends, and black dots to no trend. Stations with a significant trend at the 0.05 level are shown by being surrounded by a black square. 
Table 2. Trend magnitudes per decade (95\% confidence intervals in parentheses) for regional indices of extreme precipitation, 1975-2014 (values for trends significant at the 0.05 level are in bold). Percentage of stations (bold) and percentage of stations with a significant trend (at 0.05 level) (italics) are indicated in parenthesis, for both negative and positive trends for annual extreme precipitation indices, from 1975-2014.

\begin{tabular}{|c|c|c|c|c|c|}
\hline Index & Units & Trend Magnitudes & Increasing & No Trend & Decreasing \\
\hline R10 & days per decade & $0.27 \pm 0.07(-0.12,0.41)$ & $42(50.6 \%, 9.6 \%)$ & $31(37.3 \%)$ & $10(\mathbf{1 2} \%, 1.2 \%)$ \\
\hline $\mathrm{R} 20$ & days per decade & $0.07 \pm 0.03(0.01,0.13)$ & $54(65.1 \%, 8.4 \%)$ & $6(7.2 \%)$ & $23(27.7 \%, 1.2 \%)$ \\
\hline $\mathrm{R} \times 1 \mathrm{~d}$ & mm per decade & $0.45 \pm 0.12(0.21,0.68)$ & $55(66.3 \%, 8.4 \%)$ & $2(2.4 \%)$ & $26(31.3 \%, 0.0 \%)$ \\
\hline $\mathrm{R} \times 5 \mathrm{~d}$ & mm per decade & $\mathbf{0 . 5 0} \pm 0.24(0.03,0.97)$ & $49(59.0 \%, 4.8 \%)$ & $1(1.2 \%)$ & $33(39.8 \%, 1.2 \%)$ \\
\hline CDD & days per decade & $-0.87 \pm 0.51(-1.89,0.16)$ & $34(41.0 \%, 3.6 \%)$ & $4(4.8 \%)$ & $45(54.2 \%, 0.0 \%)$ \\
\hline CWD & days per decade & $-0.02 \pm 0.03(-0.07,0.03)$ & $13(\mathbf{1 5 . 7} \%, 0.0 \%)$ & $58(69.9 \%)$ & $12(\mathbf{1 4 . 5} \%, 3.6 \%)$ \\
\hline R95p & mm per decade & $3.24 \pm 0.88(1.49,4.99)$ & $54(65.0 \%, 8.4 \%)$ & $7(8.4 \%)$ & $22(26.5 \%, 0.0 \%)$ \\
\hline $\mathrm{R} 99 \mathrm{p}$ & mm per decade & $1.96 \pm 0.53(0.91,3.01)$ & $57(68.7 \%, 8.4 \%)$ & $0(\mathbf{0 . 0} \%)$ & $26(31.3 \%, 0.0 \%)$ \\
\hline PRCPTOT & mm per decade & $6.98 \pm 1.60(3.80,10.16)$ & $62(74.7 \%, 15.6 \%)$ & $0(\mathbf{0 . 0} \%)$ & $21(25.3 \%, 0.0 \%)$ \\
\hline SDII & $\left(m m\right.$ day $\left.^{-1}\right)$ per decade & $0.08 \pm 0.01(0.05,0.11)$ & $54(65.1 \%, 10.8 \%)$ & $1(\mathbf{1 9 . 3 \% )}$ & $13(15.7 \%, 0.0 \%)$ \\
\hline
\end{tabular}

\subsubsection{Absolute Indices}

For the entire QTP, maximum one-day precipitation amounts $(\mathrm{R} \times 1 \mathrm{~d})$ and maximum five-day precipitation amounts $(\mathrm{R} \times 5 \mathrm{~d})$ recorded significant increases (Figure $2 \mathrm{c}, \mathrm{d})$; average magnitudes of 0.45 and $0.50 \mathrm{~mm} /$ decade, respectively, were recorded. These two indices had similar fluctuations: from 1975-2005 they both fluctuated before rapidly increasing after 2005.

Weather stations recording increasing trends for $\mathrm{R} \times 1 \mathrm{~d}$ ( $66.3 \%$ of stations; magnitude of 0.05 to $2.88 \mathrm{~mm} /$ decade), although generally being distributed across the plateau, had a number centered on the area of the Three-River source and in northeastern areas. However, only seven stations recorded a significant trend at the $95 \%$ confidence level (Figure 3c, Table 2). Results for $\mathrm{R} \times 5 \mathrm{~d}$ showed that $59.0 \%$ of stations (49 stations) had an increasing trend; the spatial distribution of these stations were scattered across the QTP. The recorded magnitudes ranged from 0.03 to $4.64 \mathrm{~mm} /$ decade, although only four stations were found to be significant (Table 2). In addition, 33 stations recorded a decreasing trend; these stations were centered on the eastern and southern areas of the plateau (Figure 3d, Table 2).

\subsubsection{Duration Indices}

Records for consecutive dry days (CDD) and consecutive wet days (CWD) showed a decreasing trend in the QTP from 1975-2014, with an average magnitude of -0.87 and $-0.02 \mathrm{~d} /$ decade, respectively. Neither result was found to be significant (Table 2). CDD had a decreasing trend from 1975 to 1990, after which the trend increased. CWD however recorded large fluctuations from 1975 to 2000. Results after the year 2000 then showed a decrease of CWD until 2010 (Figure 2e).

The spatial trends for CDD are shown in Figure 3e. Results showed that $41.0 \%$ of stations recorded increasing trends, these stations predominantly being distributed in the southern plateau area. The magnitudes from these stations ranged from 0.34 to $9.06 \mathrm{~d}$ /decade, with only three stations having a significant trend (7.27, 7.50 and $8.33 \mathrm{~d}$ /decade for Nielaer, Jiulong and Linzhi, respectively). A decreasing trend was identified for $54.2 \%$ of stations, these being centered on the central, eastern and northern plateau areas. Results for these decreasing trends were found to not be significant at the 0.05 level.

A remarkable feature of CWD was that almost 70\% of stations showed no trend (Figure 3f). Twelve stations with increasing trends were mainly located in the central QTP, with some stations being sporadically distributed in the northern and western areas. Thirteen stations recorded a decreasing trend and they were mainly located in the eastern areas; of these, only three stations were found to be significant, having magnitudes ranging from -0.84 to $-0.47 \mathrm{~d} /$ decade. 


\subsubsection{Percentile-Based Indices}

Across the whole of the plateau, very wet day precipitation (R95p) and extremely wet day precipitation (R99p) had an obvious increasing trend over the investigation period, with an average magnitude of 3.24 and $1.96 \mathrm{~mm} /$ decade, respectively. However, R99p was significant, while R95p was not significant (Table 2). In general, both indices had similar fluctuations.

Results for R95p showed that 54 stations ( $65.0 \%$ of stations), located across the study region, recorded increasing trends, ranging from 0.13 to $21.05 \mathrm{~mm} /$ decade. However, only seven of these stations were significant at the $95 \%$ confidence level (Table 2).Twenty two stations with decreasing trends were identified across the plateau, the majority of which were located in the eastern and southern regions. None of these stations however were found to be significant. Moreover, seven stations located in the Qaidam Basin and southwestern QTP identified no trend.

Results for R99p recorded decreasing trends for $31.3 \%$ of the stations, these being predominantly distributed in the eastern and southern plateau areas. Although an increasing trend was identified for $68.7 \%$ of stations, having magnitudes of $0.05-14.7 \mathrm{~mm} /$ decade, only seven stations had a significant increasing trend (Table 2).

\subsubsection{Other Indices}

Across the entire plateau, a significant increase was observed in the annual total wet-day precipitation (PRCPTOT) with a magnitude of $6.98 \mathrm{~mm} /$ decade over the past 40 years, while the simple daily intensity index (SDII) had a weak and insignificant increase (Table 2). In general, both indices had similar fluctuations.

Results for PRCPTOT showed that $74.7 \%$ of stations recorded an increasing trend, these stations being distributed across the study area. Of these stations, 15.6\% (mainly located in the central areas of the plateau) recorded significant increases, having a magnitude ranging from 15.5 to $33.3 \mathrm{~mm} /$ decade (Figure 3i). Stations which recorded decreasing trends, with magnitudes ranging from -0.15 to $-59.34 \mathrm{~mm}$ /decade, were distributed in the east and south periphery of the plateau. None of these stations were found to be significant (Figure 3i).

Results for SDII showed increasing trends at 54 stations, covering most of study area. Among these stations, nine locations were shown to have a statistically significant trend (Figure 3j); the magnitude of trend ranged from 0.02 to $0.36 \mathrm{~mm} \mathrm{day}^{-1} /$ decade. Decreasing trends were identified at 12 stations that were scattered across the plateau; however, none of these stations were found to be statistically significant. In addition, 16 stations recorded no trend over the study period.

\subsection{Contribution of Extreme Precipitation to Total Precipitation}

The results showed that the contribution of extreme precipitation to total precipitation generally increased from 1975-2014, although there were large fluctuations in the data (Figure 4a,b). Precipitation on very wet days accounted for an average of $18.6 \%$ of total precipitation (ranging from 15.4 to $22.5 \%$; Figure $4 a)$ with a significant positive trend $(0.06 \%$ /decade) at the 0.05 level. The average contribution in the extremely wet days was $5.2 \%$ (ranging from 2.8 to $8.1 \%$; Figure $4 \mathrm{~b}$ ) with a significant trend $(0.05 \%$ /decade $)$ at the 0.05 level.

Spatial distribution of R95pT showed that stations recording an increasing trend (57.8\% of stations) were mainly distributed in the Three-River source area, the middle reaches of the YaluZangbo River, the southeast and northeast periphery of the plateau (Figure 4c). However, only eight stations were found to have a significant trend. Stations which recorded a decreasing trend, with magnitudes of -0.13 to $-2.91 \%$ / decade, were distributed in the central and eastern areas of the plateau; none of these stations however were found to be significant. Six weather stations, predominantly located in the Qaidam Basin and to the southwest of the plateau, did not record a trend across the study period.

With respect to $\mathrm{R} 99 \mathrm{pT}$, increasing trends were recorded for $63.8 \%$ of stations. These stations were mainly centered on the Qaidam Basin, the middle reaches of the YaluZangbo River, the source of 
the Yangtze and Lancang rivers, the southeast and northeast periphery of the plateau (Figure 4d). Thirty stations were identified as having decreasing trends across the study period, scattered across the plateau, however none of these stations recorded a statistically significant trend.
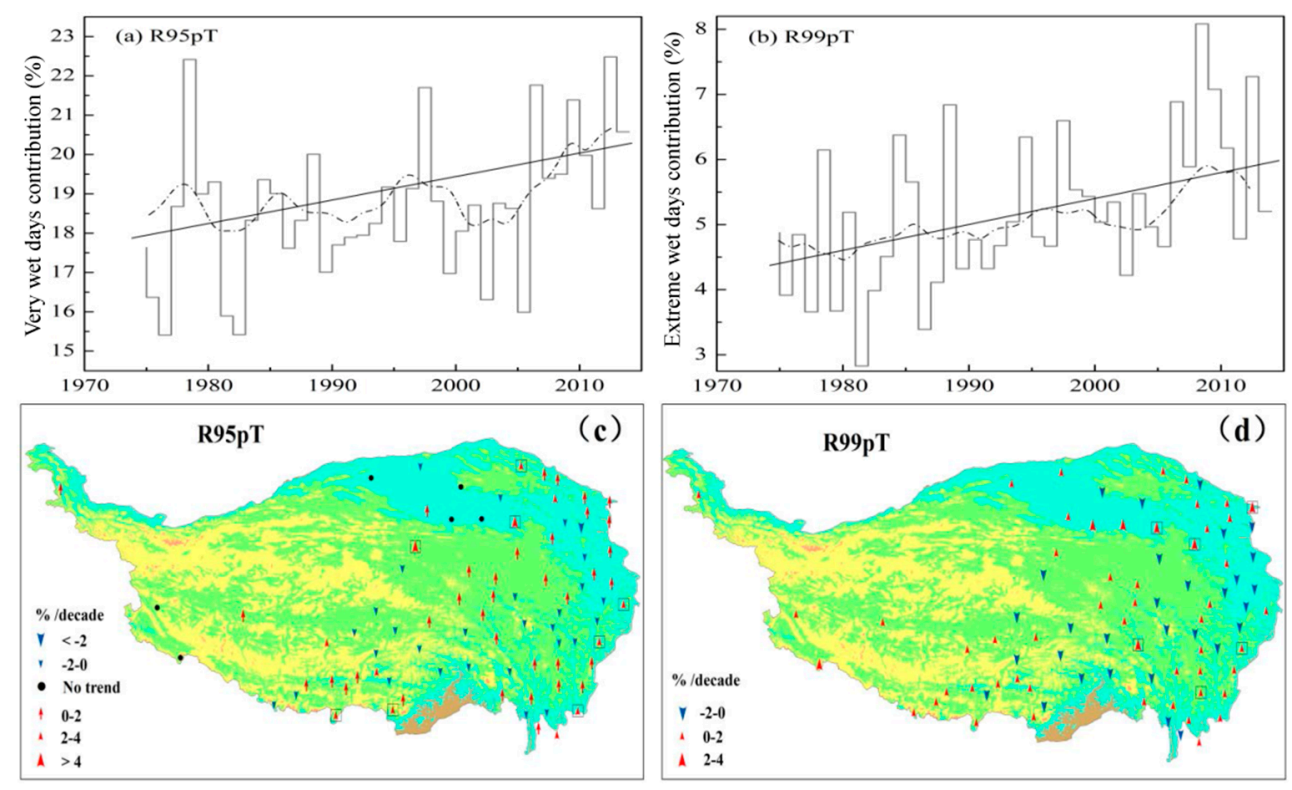

Figure 4. Regional series and spatial distribution for the percentage of the index of precipitation on very wet days to total precipitation (R95pT) and the ratio of the index of precipitation on extremely wet days to total precipitation (R99pT). (a) Regional series for very wet days contribution; (b) Regional series for extremely wet days contribution. The dotted line is the five-year smoothing average and the black line is the linear trend; (c) Spatial distribution for very wet days contribution; (d) Spatial distribution for extremely wet days contribution. Signs are scaled according to the magnitude of trend. Color coding is as follows: blue corresponds to decreasing trends, red to increasing trends and black dots indicate no trend. Stations with a significant trend at the 0.05 level are shown surrounded by black squares.

\subsection{Relationship between Precipitation Extremes and Topography}

Table 3 illustrates the correlation coefficients between the trend magnitudes in extreme precipitation indices and elevation. Among these indices, only PRCPTOT was found a statistically significant positive correlation with the elevation at a $95 \%$ confidence level. Negative correlations were observed for CDD and SDII, but not significant. Besides the above three indices, a positive and insignificant correlations were shown.

Table 3. Correlation coefficients between the trends of extreme precipitation indices and elevation.

\begin{tabular}{ccccccccccc}
\hline Indices & $\mathbf{R 1 0}$ & $\mathbf{R 2 0}$ & $\mathbf{R} \times \mathbf{1 d}$ & $\mathbf{R} \times \mathbf{5 d}$ & $\mathbf{C D D}$ & $\mathbf{C W D}$ & $\mathbf{R 9 5 P}$ & $\mathbf{R 9 9 P}$ & $\mathbf{P R C P T O T}$ & SDII \\
\hline Coefficient & 0.079 & 0.110 & 0.090 & 0.077 & -0.116 & 0.112 & 0.068 & 0.126 & $0.362 *$ & -0.056 \\
\hline \multicolumn{10}{c}{$*$ significant at 0.05 significance level. }
\end{tabular}

Table 4 shows the average trend magnitudes of each index in the categorized elevation groups. There are six indices with the largest trend magnitudes appearing at 4501-5000 m. Among them, $\mathrm{R} 10, \mathrm{R} \times 1 \mathrm{~d}, \mathrm{R} \times 5 \mathrm{~d}, \mathrm{R} 95 \mathrm{p}$, and PRCPTOT displayed a positive trend, and CDD had a negative trend. For R20, the largest trend magnitude existed at $4001-4500 \mathrm{~m}$. For R99p and SDII, the positive trends were shown in the all elevation groups, and the largest trend magnitudes emerged at 3001-3500 $\mathrm{m}$ and $<2500 \mathrm{~m}$, respectively. The largest trend magnitude for CWD existed at 2501-3000 m, with a negative 
trend. To investigate the impact of different elevation groups on the extreme indices, non-parametric Kruskal-Wallis test was performed. The results show that there was no significant difference between the elevation groups and precipitation extreme indices except for PRCPTOT. In addition, the trend of each extreme indices showed a different fluctuation with elevation, which also showed that elevation had a little effect on the change in precipitation extreme indices. Only the change of PRCPTOT was affected by the elevation.

Table 4. Average trend magnitudes of extreme precipitation in the categorized elevation groups.

\begin{tabular}{ccccccc}
\hline Precipitation Extremes & $\mathbf{< 2 5 0 0}$ & $\mathbf{2 5 0 1 - 3 0 0 0}$ & $\mathbf{3 0 0 1 - 3 5 0 0}$ & $\mathbf{3 5 0 1 - 4 0 0 0}$ & $\mathbf{4 0 0 1 - 4 5 0 0}$ & $>\mathbf{4 5 0 1}$ \\
\hline Number of Stations & 9 & 19 & 17 & 18 & 14 & 6 \\
R10 & -0.30 & 0.45 & 0.24 & 0.22 & 0.24 & $\mathbf{0 . 7 8}$ \\
R20 & -0.01 & 0.05 & 0.07 & 0.06 & $\mathbf{0 . 1 4}$ & 0.09 \\
R $\times$ 1d & 0.35 & 0.11 & 0.81 & 0.45 & 0.37 & $\mathbf{0 . 8 2}$ \\
R $\times \mathbf{5 d}$ & -1.22 & 0.41 & 0.94 & 0.84 & 0.37 & $\mathbf{1 . 4 4}$ \\
R95P & 3.85 & 2.29 & 3.26 & 2.83 & 3.63 & $\mathbf{5 . 9 9}$ \\
R99P & 2.53 & 0.82 & $\mathbf{2 . 6 5}$ & 2.20 & 1.75 & 2.54 \\
CDD & 0.56 & -0.86 & -1.10 & 0.46 & -1.79 & -3.86 \\
CWD & -0.16 & $-\mathbf{0 . 5 2}$ & -0.07 & 0.06 & 0.01 & -0.05 \\
PRCPTOT & -9.42 & 4.40 & 4.26 & 10.57 & 11.38 & $\mathbf{2 6 . 3 9}$ \\
SDII & $\mathbf{0 . 1 2}$ & 0.07 & 0.09 & 0.08 & 0.05 & 0.10 \\
\hline
\end{tabular}

The bold is the maximum magnitude for each indices. The units are same as Table 2.

Table 5 shows the average trend magnitudes of each index in categorized topographic group. For R10, R99p, CDD, CWD and SDII, the largest trend magnitude appear at the flat group. For R20, $\mathrm{R} \times 1 \mathrm{~d}, \mathrm{R} \times 5 \mathrm{~d}$, R95p and PRCPTOT, the largest value of trend magnitudes occurred at the hill group. In general, the trend magnitude was more obvious at flat and hill groups than in that of mesa and low rolling mountain groups. Further, the trend magnitudes were lower in low rolling mountain groups than in that of other groups. Overall, each trend of extreme indices showed a different fluctuation with the topography. According to non-parametric Kruskal-Wallis test, only the change of PRCPTOT was affected significantly by the topography $(p=0.038)$.

Table 5. Average trend magnitudes of precipitation extremes in the categorized topographic groups.

\begin{tabular}{ccccc}
\hline Precipitation Extremes & Flat & Mesa & Hill & Low Rolling Mountain \\
\hline Number of Stations & 29 & 21 & 17 & 16 \\
R10 & $\mathbf{0 . 4 7}$ & 0.14 & 0.33 & -0.01 \\
R20 & 0.11 & 0.03 & $\mathbf{0 . 1 3}$ & -0.04 \\
R $\times \mathbf{1 d}$ & 0.58 & 0.26 & $\mathbf{0 . 6 2}$ & 0.27 \\
$\mathbf{R} \times \mathbf{5 d}$ & 0.37 & 0.77 & $\mathbf{1 . 2 5}$ & -0.40 \\
R95p & 4.02 & 2.83 & $\mathbf{5 . 6 2}$ & -0.01 \\
R99p & $\mathbf{2 . 6 7}$ & 0.92 & 2.25 & 1.72 \\
CDD & $\mathbf{- 1 . 6 9}$ & -0.36 & -1.23 & 0.48 \\
CWD & $\mathbf{- 0 . 3 6}$ & -0.07 & 0.09 & -0.07 \\
PRCPTOT & 9.51 & 6.22 & $\mathbf{1 2 . 4 0}$ & -2.38 \\
SDII & $\mathbf{0 . 1 0}$ & 0.06 & 0.08 & 0.07 \\
\hline
\end{tabular}

The bold is the maximum magnitude for each indices. The units are same as Table 2.

\section{Discussion}

Climatologically, QTP is affected by large-scale circulations of monsoons and the westerlies. These weather systems not only have a major influence upon precipitation changes in this area, but the strength of these systems directly controls their respective effect-ranges [53]. In our study area, summer precipitation accounted for more than $60 \%$ of annual total precipitation over the QTP; this decreased from the southeastern to the northwestern regions of the plateau [54]. Investigations by Chen et al. [18] 
and Dong et al. [55] have shown that the influence of the South Asian Summer Monsoon (SASM) affects summer precipitation in the southwestern part of the QTP due to its effect on deep-convective systems in the Indian plain. The southeastern area of the QTP is also controlled by the SASM. In our study, the extreme indices, such as $R \times 1 d, R \times 5 d$, R95p, R99p, and PRCPTOT indicated a decreasing trend in the southern part of the plateau, especially in the southeastern area, which may have been caused by a decrease in the SASM (Figure 5a).The climate of the eastern area of the QTP is mainly controlled by the East Asian Summer Monsoon (EASM), located in the northern Sichuan province and the southern Gansu province. Figure 5b shows that EASM had an obvious decreasing trend during the study period, which may have been the cause of the decrease of precipitation extremes in this area (including $\mathrm{R} \times 1 \mathrm{~d}, \mathrm{R} \times 5 \mathrm{~d}, \mathrm{R} 95 \mathrm{p}$, R99p and PRCPTOT). In the north and western areas of the plateau, including the Qidam basin, Kunlun and Qilian Mountain areas, extreme precipitation, including R10,

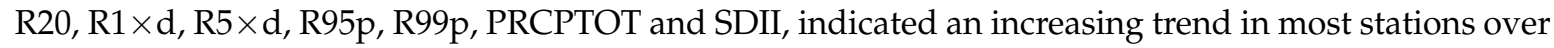
the past 40 years. Liu and Duan [53] identified that precipitation on the QTP, especially in the north and western areas, is affected by the North Atlantic Oscillation (NAO), and the increased precipitation in the northern plateau areas were linked to enhanced NAO activity. Temporally, all indices showed an increasing trend except for CDD and CWD during 1975-2014, and similar trends in the extreme precipitation have been observed in different parts of the world [56-58]. Indices such as R10, $R \times 1 \mathrm{~d}$, and $\mathrm{R} \times 5 \mathrm{~d}$ exist in contradiction with the results of the adjacent Loess plateau [7], Yunnan Province [12], and the eastern and central QTP [26], Hengduan Mountains [29]. These differences were probably due to the analysis period and the spatial domains, which highlights the less spatial coherence of precipitation and the importance of trend analysis at a regional scale. Moreover, the contribution of R95p and R99p to total precipitation also increased significantly (0.06 and 0.05\%/decade, respectively). In general, results for the precipitation extremes showed an increasing trend across the QTP.
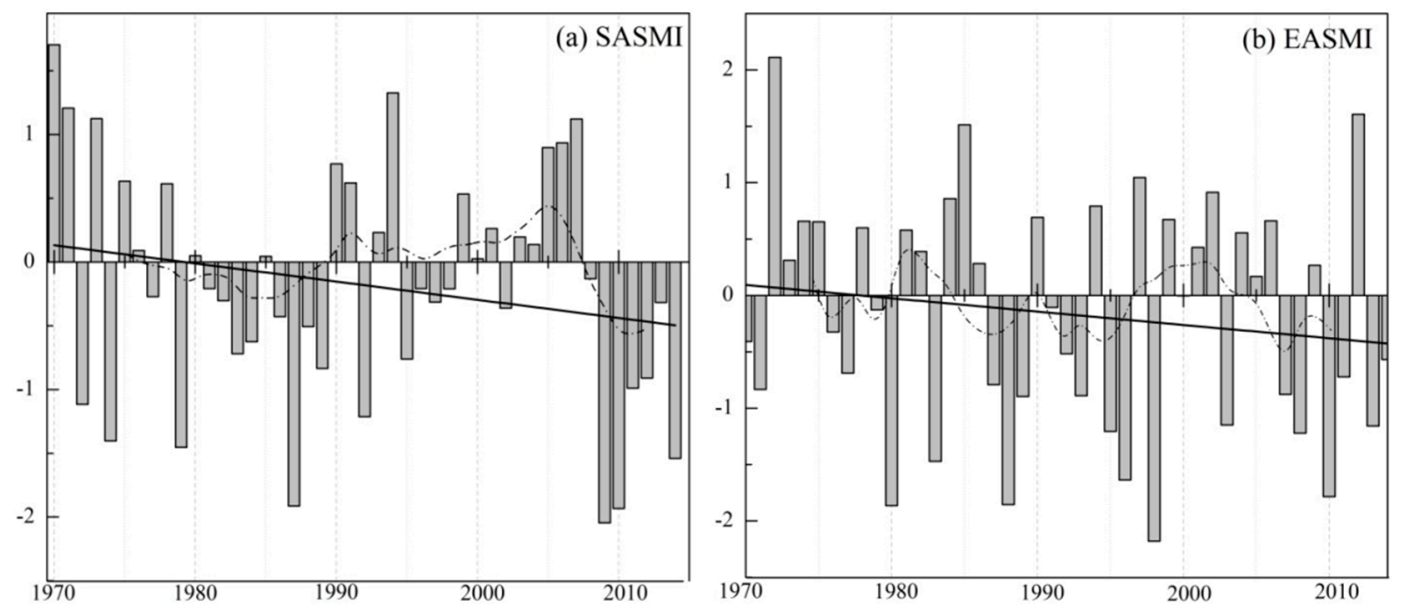

Figure 5. Normalized South Asian Summer Monsoon Index (a) and East Asian Summer Monsoon Index (b) during 1970-2014. The dash dotted line is the five-year smoothing average and the black line is the linear trend.

In addition to the large-scale atmospheric circulations and local hydrological cycles, the topography may also partly exert an important impact on the extreme precipitation in the QTP. In some studies, the topography was considered to be an important influencing factor for precipitation change. Sanchez-Moreno et al. [59] found that elevation had little effect on high and more extreme rainfalls, while low and medium rainfall events were significantly affected by orography, with most of the rainfall appearing on high elevations in Santiago Island, Africa. Koinrad, II [60] also found that elevation is strongly associated with light precipitation events. Hession and Moore [61] found that rainfall was strongly influenced by elevation and slope during the 'long rains' and 'short rains'. In this study, elevation was not found to be a significant effect on the change of extreme precipitation except 
for PRCPTOT, which was similar to the above studies. However, there were larger trend magnitudes in the higher elevation stations than that of lower elevation stations in most of the extreme indices, which may have been caused by more melting snow and an accelerated hydrological cycle, as more rapid warming occurred at higher elevations than in lower elevations [62].The relief amplitude also had different effect on the trends of extreme precipitations. In particular, these changes of extreme precipitations were more obvious in the flat and hill groups, which may be attributed to the uplift effect of increased relief amplitude on the variation of the airflow.

\section{Conclusions}

Daily precipitation data from 83 meteorological stations on the Qinghai-Tibetan Plateau, from 1975 to 2014, has enabled temporal trends and spatial distribution in 10 indices of extreme precipitation to be analyzed using the Mann-Kendall test and Sen's slope estimator. On the spatial scale, more than $50 \%$ of stations showed increasing trends for the majority of indices, while only a few stations had significant trends. Stations with increasing trends were distributed across the majority of the study area, while stations with decreasing trends were mainly concentrated in the eastern and southeastern areas of the plateau. Temporal results for all indices exhibited increasing trends except for consecutive dry days (CDD) and consecutive wet days (CWD) during the study period, while only maximum one-day precipitation amounts $(R \times 1 d)$, maximum five-day precipitation amounts $(R \times 5 d)$, extremely wet day precipitation (R99p) and annual total wet-day precipitation (PRCPTOT) were statistically significant, with a magnitude of $0.45,0.5,1.96$ and $6.98 \mathrm{~mm} /$ decade, respectively. Results also showed that the average precipitation contribution of very wet days and extremely wet days to total precipitation showed a significantly increasing trend with 0.06 and $0.05 \%$ /decade, respectively. These findings may be due to the complex interaction between the monsoon circulation, variations of the NAO, and topography. In general, the frequency, intensity and volume of precipitation extremes all increased, leading to wetter conditions. Furthermore, only PRCPTOT presented a statistically positive correlation with elevation, indicating that extreme precipitation does not possess altitude dependency in QTP. Similarly, only topography has a significant effect on changes in PRCPTOT. However, the largest trend magnitude for most extreme precipitation indices mainly concentrated at higher elevations, and hill and flat stations, indicating that changes of extreme precipitation in these stations are more obvious than that of other topographical stations. Our results provide a foundation for further analyses of precipitation extreme events and their related impacts in the QTP.

Supplementary Materials: Supplementary materials can be found at www.mdpi.com/2073-4433/8/7/127/s1.

Acknowledgments: This research was supported by the Fundamental Research Funds of CAF (CAFYBB2017ZA006), the International Science \& Technology Cooperation Program of China (2015DFR31130), the National Key Research and Development Program of China (2016YFC0500801; 2016YFC0500804; 2016YFC0500908), and the National Natural Science Foundation of China (31670715; 41471029; 41271033; 41371500).

Author Contributions: Genbatu Ge, Zhongjie Shi, and Xiaohui Yang conceived the study; Yanshu Liu, Xiao Zhang, Fandjinou Kossi, Zhiming Xin, Wei Wei, Zhiyong Zhang contributed to analysis and manuscript preparation; Genbatu Ge and Zhongjie Shi processed and wrote the paper; Yuguang Hao, Hao Guo and Junhui, Liu helped perform the analysis with constructive discussions; Zhongjie Shi and Xiaohui Yang contributed to the revision of the paper.

Conflicts of Interest: The authors declare no conflict of interest.

\section{References}

1. Katz, R.W.; Brown, B.G. Extreme events in a changing climate: Variability is more important than averages. Clim. Chang. 1992, 3, 289-302. [CrossRef]

2. Salinger, M.J.; Griffiths, G.M. Trends in New Zealand daily temperature and rainfall extremes. Int. J. Climatol. 2001, 21, 1437-1452. [CrossRef]

3. López-Moreno, J.I.; Vicente-Serrano, S.M.; Angulo-Martínez, M.; Beguería, S.; Kenawy, A. Trends in daily precipitation on the northeastern Iberian Peninsula, 1955-2006. Int. J. Climatol. 2010, 30, 1026-1041. [CrossRef] 
4. Bennett, K.E.; Walsh, J.E. Spatial and temporal changes in indices of extreme precipitation and temperature for Alaska. Int. J. Climatol. 2015, 35, 1434-1452. [CrossRef]

5. Ji, Y.; Zhou, G.; Wang, S.; Wang, L. Increase in flood and drought disasters during 1500-2000 in Southwest China. Nat. Hazards 2015. [CrossRef]

6. Liu, M.; Xu, X.; Sun, Y.A.; Wang, K.; Liu, W.; Zhang, X. Is southwestern China experiencing more frequent precipitation extremes? Environ. Res. Lett. 2014, 9, 064002. [CrossRef]

7. Gao, Y.; Feng, Q.; Wei, L.; Lu, A.; Wang, Y.; Yang, J.; Cheng, A.; Wang, Y.; Su, Y.; Liu, L.; et al. Changes of daily climate extremes in Loess Plateau during 1960-2013. Quatern. Int. 2015, 37, 15-21.

8. Alexander, L.V.; Zhang, X.; Peterson, T.C.; Caesar, J.; Gleason, B.; Klein Tank, A.; Haylock, M.; Collins, D.; Trewin, B.; Rahimzadeh, F.; et al. Global observed changes in daily climate extremes of temperature and precipitation. J. Geophys. Res. 2006, 111, D05109. [CrossRef]

9. Groisman, P.Y.; Knight, R.W.; Easterling, D.R.; Karl, T.R.; Hegerl, G.C.; Razuvaev, V.N. Trends in Intense Precipitation in the Climate Record. J. Clim. 2005. [CrossRef]

10. Peterson, T.C.; Zhang, X.B.; Brunt-India, M.; Vázquez-Aguirre, J.L. Changes in North American extremes derived from daily weather data. J. Geophys. Res. Atmos. 2008, 113, D07113. [CrossRef]

11. You, Q.; Kang, S.; Aguilar, E.; Pepin, N.; Fludel, W.-A.; Yan, Y.; Xu, Y.; Zhang, Y.; Huang, J. Changes in daily climate extremes in China and their connection to the large scale atmospheric circulation during 1961-2003. Clim. Dynam. 2010, 36, 2399-2417. [CrossRef]

12. Li, Y.G.; He, D.; Hua, J.M.; Cao, J. Variability of extreme precipitation over Yunnan Province, China 1960-2012. Int. J. Climatol. 2015, 35, 245-258. [CrossRef]

13. Choi, G.; Collins, D.; Ren, G.; Trewin, B.; Baldi, M.; Fukuda, Y.; Afzaal, M.; Pianmana, T.; Gomboluudev, P.; Huong, P.; et al. Changes in means and extreme events of temperature and precipitation in the Asia-Pacific Network region, 1955-2007. Int. J. Climatol. 2009, 29, 1906-1925. [CrossRef]

14. Moberg, A.; Jones, P.D.; Lister, D.; Walther, A.; Brunet, M.; Jacobeit, J.; Alexander, L.V.; Della-Marta, P.M.; Luterbacher, J.; Yiou, P.; et al. Indices for daily temperature and precipitation extremes in Europe analyzed for the period 1901-2000. J. Geophys. Res. 2006, 111, D22106. [CrossRef]

15. Ye, D.; Gao, Y. The Meteorology of the Qinghai-Xizang (Tibet) Plateau; Science Press: Beijing, China, 1979; pp. 1-278. (In Chinese)

16. Hsu, H.H.; Liu, X. Relationship between the Tibetan Plateau heating and East Asian summer monsoon rainfall. Geophys. Res. Lett. 2003. [CrossRef]

17. Kang, S.; Xu, Y.; You, Q.; Fl“ugel, W.A.; Pepin, N.; Yao, T. Review of climate and cryospheric change in the Tibetan Plateau. Environ. Res. Lett. 2010, 5, 015101. [CrossRef]

18. Chen, B.; Xu, X.; Yang, S.; Zhang, W. On the origin and destination of atmospheric moisture and air mass over the Tibetan Plateau. Theor. Appl. Climatol. 2012, 110, 423-435. [CrossRef]

19. Xu, X.; Lu, C.; Shi, X.; Gao, S. World water tower: An atmospheric perspective. Geophys. Res. Lett. 2008. [CrossRef]

20. Shen, M.; Piao, S.; Cong, N.; Zhang, G.; Jassens, I.A. Precipitation impacts on vegetation spring phenology on the Tibetan Plateau. Glob. Chang. Biol. 2015. [CrossRef] [PubMed]

21. Tao, S.; Ding, Y. Observational evidence of the influence of the Qinghai-Xizang (Tibet) Plateau on the occurrence of heavy rain and severe convective storms in China. Bull. Am. Meterol. Soc. 1981, 62, 23-30. [CrossRef]

22. Wang, B.; Bao, Q.; Hoskins, B.; Wu, G.; Liu, Y. Tibetan Plateau warming and precipitation change in East Asia. Geophys. Res. Lett. 2008, 35, L14702. [CrossRef]

23. IPCC Climate Change. The Physical Science Basis. In Contribution of Working Group I to the Fourth Assessment Report of the Intergovernmental Panel on Climate Change; Cambridge University Press: Cambridge, UK, 2007.

24. Huang, M.; Peng, G.B.; Leslie, L.M.; Shao, X.M.; Sha, W.Y. Seasonal and regional temperature changes in China over the 50 year period 1951-2000. Meteorol. Atmos. Phys. 2005, 89, 105-115. [CrossRef]

25. Xu, Z.X.; Gong, T.L.; Li, J.Y. Decadal trend of climate in the Tibetan Plateau-regional temperature and precipitation. Hydrol. Process. 2008, 22, 3056-3065. [CrossRef]

26. You, Q.; Kang, S.; Aguilar, E.; Yan, Y. Changes in daily climate extremes in the eastern and central Tibetan Plateau during 1961-2005. J. Geophys. Res. 2008, 113, D07101. [CrossRef]

27. Li, Z.X.; He, Y.; Wang, P.; Theakstone, W.H.; An, W.; Wang, X.; Lu, A.; Zhang, W.; Cao, W. Changes of daily climate extremes in southwestern China during 1961-2008. Glob. Planet. Chang. 2012, 80, 255-272. 
28. Wang, S.; Zhang, M.; Wang, B.; Sun, M.; Li, X. Recent changes in daily extremes of temperature and precipitation over the western Tibetan Plateau, 1973-2011. Quatern. Int. 2013, 313, 110-117. [CrossRef]

29. Zhang, K.; Pan, S.; Cao, L.; Wang, Y.; Zhao, Y.; Zhang, W. Spatial distribution and temporal trends in precipitation extremes over the Hengduan Mountains region, China, from 1961 to 2012. Quatern. Int. 2014, 349, 346-356. [CrossRef]

30. Maussion, F.; Scherer, D.; Mölg, T.; Collier, E.; Curio, J.; Finkelnburg, R. Precipitation Seasonality and Variability over the Tibetan Plateau as Resolved by the High Asia Reanalysis. J. Clim. 2014, 27, 1910-1927. [CrossRef]

31. You, Q.; Fraedrich, K.; Ren, G.; Ye, B.; Meng, X.; Kang, S. Inconsistencies of precipitation in the eastern and central Tibetan Plateau between surface adjusted data and reanalysis. Theor. Appl. Climatol. 2012, 109, 485-496. [CrossRef]

32. Long, Q.; Chen, Q.; Gui, K.; Zhang, Y. A Case Study of a Heavy Rain over the Southeastern Tibetan Plateau. Atmosphere 2016, 7, 118. [CrossRef]

33. Li, Z.; He, Y.; Theakstone, W.H.; Wang, X.; Zhang, W.; Cao, W.; Du, J.; Xin, H.; Chang, L. Altitude dependency of trends of daily climate extremes in southwestern China, 1961-2008. J. Geogr. Sci. 2012, 22, 416-430. [CrossRef]

34. Ji, Z.; Kang, S.; Cong, Z.; Zhang, Q.; Yao, T. Simulation of carbonaceous aerosols over the Third Pole and adjacent regions: Distribution, transportation, deposition, and climatic effects. Clim. Dynam. 2015, 45, 2831-2846. [CrossRef]

35. Qiu, J. Environment: Riding on the roof of the world. Nature 2007, 449, 398-402. [CrossRef] [PubMed]

36. Wan, W.; Xiao, P.; Feng, X.; Li, H.; Ma, R.; Duan, H.; Zhao, L. Monitoring lake changes of Qinghai-Tibetan Plateau over the past 30 years using satellite remote sensing data. Chin. Sci. Bull. 2014, 59. [CrossRef]

37. Zhao, Z.; Zhang, Y.; Liu, L.; Liu, F.; Zhang, H. Recent changes in wetlands on the Tibetan Plateau: A review. J. Geogr. Sci. 2015, 25, 879-896. [CrossRef]

38. Wan, G.; Yang, M.; Liu, Z.; Wang, X.; Liang, X. The Precipitation Variations in the Qinghai-Xizang (Tibetan) Plateau during 1961-2015. Atmosphere 2017, 8, 80. [CrossRef]

39. WMO. Calculation of Monthly and Annual 30-Year Standard Normals; WCDP-No.10, WMO-TD/No. 34; World Meteorological Organization: Geneva, Switzerland, 1989; p. 11.

40. Zhang, X.; Feng, Y. RClimDex (1.0) User Manual. Available online: http:/ / etccdi.pacificclimate.org/software. shtml (accessed on 10 September 2004).

41. Aguilar, E.; Auer, I.; Brunet, M.; Peterson, T.C.; Wieringa, J. Guidance on metadata and homogenization. Wmo. Td. 2003, 1186, 53.

42. Wang, X.L.; Feng, Y. RHtestsV4 User Manual. Available online: http:/ / etccdi.pacificclimate.org/software. shtml (accessed on 20 July 2013).

43. Xu, L.; Shi, Z.; Wang, Y.; Zhang, S.; Chu, X.; Yu, P.; Wang, Y. Spatiotemporal variation and driving forces of reference evapotranspiration in Jing River Basin, northwest China. Hydrol. Process. 2015, 23, 4846-4862. [CrossRef]

44. Shi, Z.; Shan, N.; Xu, L.; Yang, X.; Gao, J.; Guo, H.; Dong, L. Spatiotemporal variation of temperature, precipitation and wind trends in a desertification prone region of China from 1960 to 2013. Int. J. Climatol. 2016. [CrossRef]

45. Wei, W.; Shi, Z.; Yang, X.; Wei, Z.; Liu, Y.; Zhang, Z.; Ge, G.; Zhang, X.; Guo, H.; Zhang, K.; et al. Recent Trends of Extreme Precipitation and Their Teleconnection with Atmospheric Circulation in the Beijing-Tianjin Sand Source Region, China, 1960-2014. Atmosphere 2017, 8, 83. [CrossRef]

46. Mann, H.B. Nonparametric Tests against Trend. Econometrica 1945, 13, 245-259. [CrossRef]

47. Kendall, M.G. Rank Correlation Measures; Charles Griffin: London, UK, 1975.

48. Dinpashoh, Y.; Jhajharia, D.; Fakheri-Fard, A.; Singh, V.P.; Kahya, E. Trends in reference crop evapotranspiration over Iran. J. Hydrol. 2011, 399, 422-433. [CrossRef]

49. Sen, P.K. Estimates of the regression coefficient based on Kendall's tau. J. Am. Stat. Assoc. 1968, 63, 1379-1389. [CrossRef]

50. Von Storch, H. Misuses of Statistical Analysis in Climate Research Analysis of Climate Variability; Springer: Berlin/Heidelberg, Germany, 1999; pp. 11-26.

51. Yue, S.; Pilon, P.; Phinney, B.; Cavadias, G. The influence of autocorrelation on the ability to detecttrend in hydrological series. Hydrol. Process. 2002, 16, 1807-1829. [CrossRef] 
52. Han, H.; Gao, T.; Yi, H.; Yang, M.; Yan, X.; Ren, G.; Yang, J. Extraction of Relief Amplitude Based on Change Point Method: A Case Study on the Tibetan Plateau. Sci. Geogr. Sin. 2012, 1, 101-104. (In Chinese)

53. Liu, H.; Duan, K. Effects of North Atlantic Oscillation on summer precipitation over the Tibetan Plateau. J. Glaciol. Geocryol. 2012, 2, 311-318. (In Chinese)

54. Liu, X.; Yin, Z. Spatial and temporal variation of summer precipitation over the eastern Tibetan Plateau and the North Atlantic Oscillation. J. Clim. 2001, 14, 2896-2909. [CrossRef]

55. Dong, W.; Lin, Y.; Wright, J.S.; Ming, Y.; Xie, Y.; Wang, B.; Luo, Y.; Huang, W.; Huang, J.; Wang, L.; et al. Summer rainfall over the southwestern Tibetan Plateau controlled by deep convection over the Indian subcontinent. Nat. Commun. 2016, 7, 10925. [CrossRef] [PubMed]

56. New, M.; Hewitson, B.; Stephenson, D.B.; Tsiga, A.; Kruger, A.; Manhique, A.; Gomez, B.; Coelho, C.A.S.; Masisi, D.N.; Kululanga, E.; et al. Evidence of trends in daily climate extremes over southern and west Africa. J. Geophys. Res. Atmos. 2006, 111, D14102. [CrossRef]

57. Vincent, L.A.; Mekis, E. Changes in daily and extreme temperature and precipitation indices for Canada over the 20th century. Atmos. Ocean 2006, 44, 177-193. [CrossRef]

58. Rahimzadeh, F.; Asgari, A.; Fattahi, E. Variability of extreme temperature and precipitation in Iran during Recent decades. Int. J. Climatol. 2009, 29, 329-343. [CrossRef]

59. Sanchez-Moreno, J.F.; Mannaerts, C.M.; Jetten, V. Influence of topography on rainfall variability in Santiago Island, Cape Verde. Int. J. Climatol. 2014, 34, 1081-1097. [CrossRef]

60. Konrad, C.E., II. Relationships between precipitation event types and topography in the southern Blue Ridge mountains of the southeastern USA. Int. J. Climatol. 1996, 16, 49-62. [CrossRef]

61. Hession, S.L.; Moore, N. A spatial regression analysis of the influence of topography on monthly rainfall in East Africa. Int. J. Climtol. 2011, 31, 1440-1456. [CrossRef]

62. Tian, L.; Yao, T.; Li, Z.; MacClune, K.; Wu, G.; Xu, B.; Li, Y.; Lu, A.; Shen, Y. Recent rapid warming trend revealed from the isotopic record in Muztagata ice core, eastern Pamirs. J. Geophys. Res. 2006, 111, D13103. [CrossRef]

(C) 2017 by the authors. Licensee MDPI, Basel, Switzerland. This article is an open access article distributed under the terms and conditions of the Creative Commons Attribution (CC BY) license (http:/ / creativecommons.org/licenses/by/4.0/). 